\title{
A Role for the Ubiquitin-Proteasome System in Activity-Dependent Presynaptic Silencing
}

\author{
Xiaoping Jiang, ${ }^{1}$ Patricia E. Litkowski, ${ }^{1}$ Amanda A. Taylor, ${ }^{1}$ Ying Lin, ${ }^{2}$ B. Joy Snider, ${ }^{2}$ and Krista L. Moulder ${ }^{1}$ \\ Departments of ${ }^{1}$ Psychiatry and ${ }^{2}$ Neurology, Washington University School of Medicine, St. Louis, Missouri 63110
}

Chronic changes in electrical excitability profoundly affect synaptic transmission throughout the lifetime of a neuron. We have previously explored persistent presynaptic silencing, a form of synaptic depression at glutamate synapses produced by ongoing neuronal activity and by strong depolarization. Here we investigate the involvement of the ubiquitin-proteasome system (UPS) in the modulation of presynaptic function. We found that proteasome inhibition prevented the induction of persistent presynaptic silencing. Specifically, application of the proteasome inhibitor MG-132 (carbobenzoxy-L-leucyl-L-leucyl-L-leucinal) prevented decreases in the size of the readily releasable pool of vesicles and in the percentage of active synapses. Presynaptic silencing was accompanied by decreases in levels of the priming proteins Munc13-1 and Rim1. Importantly, overexpression of Rim $1 \alpha$ prevented the induction of persistent presynaptic silencing. Furthermore, strong depolarization itself increased proteasome enzymatic activity measured in cell lysates. These results suggest that modulation of the UPS by electrical activity contributes to persistent presynaptic silencing by promoting the degradation of key presynaptic proteins.

\section{Introduction}

Chronic changes in electrical excitability profoundly affect synaptic transmission during development and throughout life. Neurons adapt to changing electrical activity patterns in a plastic manner by upregulating or downregulating subsequent synaptic signaling. This activity-dependent plasticity takes on many forms, from Hebbian feedforward strengthening of synapses to homeostatic depression of global synaptic activity. Because it is of opposite polarity to the inducing stimulus, homeostatic plasticity may be an important adaptive response to prevent excitotoxicity or runaway excitation or simply to keep Hebbian mechanisms (e.g., long-term potentiation) from saturating synaptic machinery (Turrigiano and Nelson, 2004). We have described a presynaptic form of adaptive plasticity that we refer to as persistent presynaptic silencing, which operates over a wide range of activity in hippocampal neurons (Moulder et al., 2004, 2006). Presynaptically silenced neurons exhibit reduced glutamate release after a period of increased spiking or tonic depolarization. The exact mechanism responsible for decreased glutamate signaling is unknown but appears to involve compromised synaptic vesicle priming (Moulder et al., 2006).

Received 0ct. 6, 2009; revised Nov. 3, 2009; accepted Nov. 12, 2009.

This work was supported by the Howard Hughes Medical Institute Summer Undergraduate Research Fellowship program, National Institutes of Health (NIH) Grants DA018109, NS044923, and MH78823, and NIH Neuroscience Blueprint Core Grant P30NS057105 to Washington University. We thank Dr. Thomas Südhof (Stanford University, Palo Alto, (A) for the Rim1 $\alpha$ construct, Dr. Ann Marie Craig (University of British Columbia, Vancouver, British Columbia, (anada) for the synaptophysin-YFP construct, the laboratory of Dr. David Holtzman for use of their Kodak ImageStation 440 CF, Dr. John Cirrito for advice on Western blot experiments, Geraldine Kress for help with hippocampal slice preparation, Ann Benz for preparation of hippocampal cultures, and the laboratory of Dr. Steven Mennerick for advice and support.

Correspondence should be addressed to Krista L. Moulder, Washington University School of Medicine, Department of Psychiatry, 660 S. Euclid Avenue, St. Louis, M0 63110. E-mail: moulderk@psychiatry.wustl.edu.

DOI:10.1523/JNEUROSCI.4965-09.2010

Copyright $\odot 2010$ the authors $\quad 0270-6474 / 10 / 301798-12 \$ 15.00 / 0$
Recently, the synaptic vesicle priming protein $\operatorname{Rim} 1 \alpha$ has been shown to be a substrate of the ubiquitin-proteasome system (UPS) (Yao et al., 2007). The proteasome is a proven regulator of postsynaptic function, with targets including AMPA receptors, PSD-95, and the spine-associated Rap GTPase activating protein (Burbea et al., 2002; Colledge et al., 2003; Ehlers, 2003; Pak and Sheng, 2003; Patrick et al., 2003; Bingol and Schuman, 2006). The UPS also has a critical role in synaptogenesis and synapse elimination (for review, see Haas and Broadie, 2008), mediated in some settings by the ability of select ubiquitin ligases to be trafficked to specific synapses (Ding et al., 2007). Last, considerable work in invertebrate systems has demonstrated that the UPS can affect neurotransmitter release (Aravamudan and Broadie, 2003; Speese et al., 2003; Zhao et al., 2003; Fioravante et al., 2008). Despite these advances, however, research into the role of the proteasome at mammalian presynaptic sites is a nascent field. Recent work in hippocampal neurons confirms that the proteasome modulates the size of the recycling pool of synaptic vesicles in a manner likely tied to electrical activity (Willeumier et al., 2006).

We explored the hypothesis that the UPS participates in depolarization-induced persistent presynaptic silencing in hippocampal neurons. We found that presynaptic silencing was accompanied by decreases in the synaptic and cellular levels of Rim1 proteins, as well as those of another priming protein, Munc13-1. Proteasome inhibition prevented both the induction of presynaptic silencing and the decreases in Rim1 and Munc13-1 proteins. These decreases were likely attributable to increased proteasomal degradation as depolarization enhanced proteasome enzymatic activity. Finally, overexpression of $\operatorname{Rim} 1 \alpha$ also prevented induction of presynaptic silencing. We conclude that modulation of the presynaptic proteasome complex by electrical activity governs glutamate release through control of key vesicle priming proteins. 


\section{Materials and Methods}

Cell culture. Hippocampal cultures were prepared as described previously (Mennerick et al., 1995). In brief, dissected postnatal (postnatal days $0-3$ ) rat hippocampi were incubated with papain and then mechanically dissociated and plated at either $\sim 650$ cells $/ \mathrm{mm}^{2}$ as "mass" cultures or 100 cells $/ \mathrm{mm}^{2}$ on microdots of collagen as "microisland" cultures. Plating medium consisted of Eagle's medium (Invitrogen) supplemented with heat-inactivated horse serum (5\%), fetal bovine serum (5\%), $17 \mathrm{~mm}$ glucose, $400 \mu \mathrm{m}$ glutamine, $50 \mathrm{U} / \mathrm{ml}$ penicillin, and $50 \mu \mathrm{g} / \mathrm{ml}$ streptomycin. Cultures were maintained at $37^{\circ} \mathrm{C}$ in a humidified incubator with $5 \% \mathrm{CO}_{2} / 95 \%$ air. Cytosine arabinoside at $6.7 \mu \mathrm{M}$ was added at $3-4 \mathrm{~d}$ after plating to inhibit cell division. At $1 \mathrm{~d}$ (mass cultures) or $4-5 \mathrm{~d}$ (microisland cultures), a medium exchange was performed with Neurobasal medium (Invitrogen) plus B27 supplement.

Some transfection experiments were performed on microisland cultures prepared on microstamped coverslips. To prepare these cultures, $25 \mathrm{~mm}$ coverslips were shaken in $95 \%$ ethanol overnight. Coverslips were then washed with water and autoclaved, precoated with $0.15 \%$ agarose type II-A (Sigma), and allowed to dry. After drying, collagen was applied to a polydimethylsiloxane stamp (Moulder et al., 2007), which had been cleaned using a PDC-001 plasma cleaner (Harrick Plasma). The collagen was then stamped onto the coverslip and exposed to ultraviolet light for $45 \mathrm{~min}$. Cortical astrocytes (obtained as in the study by Rose et al., 1992) were plated on stamped coverslips in plating medium (above). After 3-6 d, hippocampal neurons obtained as above were plated at 25 cells $/ \mathrm{mm}^{2}$ onto the astrocyte microislands. Transfections were performed using either these microstamped coverslips (see Fig. $8 A-D$ ) or mass cultures (see Fig. $8 E$ ) (supplemental Fig. 1, available at www.jneurosci.org as supplemental material) at 9-14 d after neuronal plating using Lipofectamine 2000 (Invitrogen) (Moulder et al., 2007). Green fluorescent protein (GFP) was obtained from Genlantis, the $\operatorname{Rim} 1 \alpha$ construct was a kind gift from Dr. Thomas Südhof (Stanford University, Palo Alto, CA), and the synaptophysin-yellow fluorescent protein (YFP) construct was a kind gift from Dr. Ann Marie Craig (University of British Columbia, Vancouver, British Columbia, Canada).

Experiments were conducted at 11-14 d in vitro (DIV). Presynaptic silencing can be induced with different depolarizing stimuli, although the degree of depolarization and the time of exposure are inversely linked. For example, manipulations of neuronal spiking within the physiological range of activity require several days to depress glutamate release (Moulder et al., 2006). To avoid potential confounds (of proteasome inhibitors or other pharmacological agents) on neuronal survival (Ding and Keller, 2001; Snider et al., 2002; Reaney et al., 2006) or development, we focused here on strong stimulation, in which manipulations can be completed in a matter of hours (Moulder et al., 2004, 2008). [ $\left.\mathrm{K}^{+}\right]_{\mathrm{o}}$ was elevated from 5 to $35 \mathrm{~mm}$ for $4 \mathrm{~h}$ as indicated, with equimolar $\mathrm{NaCl}$ added to control cultures to match osmotic changes. D-2-Amino-5-phosphonovalerate (D-APV) at $25 \mu \mathrm{M}$ and $1 \mu \mathrm{M}$ 2,3-dihydroxy-6-nitro-7sulfonyl-benzo[f] quinoxyline (NBQX) were added to control and experimental dishes during this treatment, which we refer to throughout the text as "depolarization."

Hippocampal slice preparation. Some Western blotting experiments shown in Figure 7 were performed using acute hippocampal slice tissue to increase the amount of total protein available for Western blot analysis. (No other experiments used acute slices.) We have confirmed previously that persistent presynaptic silencing can be induced in acute hippocampal slices (Moulder et al., 2004). Slices were prepared as described previously (Meeks and Mennerick, 2004). In brief, anesthetized Sprague Dawley rats (14-21 d postnatal) were decapitated, and $300 \mu \mathrm{m}$ coronal slices of the hippocampus were cut with a vibratome. Slices were then held at room temperature for $60 \mathrm{~min}$ with a bath solution containing the following (in mM): $125 \mathrm{NaCl}, 2.5 \mathrm{KCl}, 1 \mathrm{MgCl}_{2}, 2 \mathrm{CaCl}_{2}, 25$ dextrose, $1.25 \mathrm{NaH}_{2} \mathrm{PO}_{4}, 0.4$ ascorbic acid, 3 myo-inositol, 2 sodium pyruvate, $25 \mathrm{NaHCO}_{3}, 2 \mathrm{~mm}$ kynurenate ( $\mathrm{pH} 7.4$ when bubbled with $95 \% \mathrm{O}_{2} / 5 \% \mathrm{CO}_{2}$ ). After this recovery period, slices were either maintained in bath solution for $4 \mathrm{~h}$ (control) or depolarized in bath solution.
Both conditions also received $25 \mu \mathrm{M}$ D-APV and $1 \mu \mathrm{M}$ NBQX. To maintain proper osmolarity, $\mathrm{NaCl}$ was reduced to $95 \mathrm{~mm}$ when the additional $30 \mathrm{~mm} \mathrm{KCl}$ was added for the depolarization.

FM1-43FX labeling and immunocytochemistry. Mass cultures plated on coverslips were used for all imaging experiments. Neurons were exposed for $2 \mathrm{~min}$ to $10 \mu \mathrm{M}$ FM1-43FX [fixable version of $N$-(3-triethylammoniumpropyl)-4-(4-(dibutylamino)styryl) pyridinium dibromide] (Invitrogen) and $45 \mathrm{mM} \mathrm{K}^{+}$(equimolar substitution for $\mathrm{Na}^{+}$) in extracellular recording saline containing the following (in $\mathrm{mM}$ ): $138 \mathrm{NaCl}, 4$ $\mathrm{KCl}, 2 \mathrm{CaCl}_{2}, 1 \mathrm{MgCl}_{2}, 10$ glucose, 10 HEPES, $0.025 \mathrm{D}-\mathrm{APV}$, and 0.001 $\mathrm{NBQX}, \mathrm{pH}$ 7.25. Cultures were washed for $5 \mathrm{~s}$ with extracellular recording saline containing $500 \mu \mathrm{M}$ Advasep-7 (CyDex) to remove nonspecific dye (Kay et al., 1999) and then washed in saline alone for $10 \mathrm{~min}$. Cultures were fixed in $4 \%$ paraformaldehyde/0.2\% glutaraldehyde in PBS, $\mathrm{pH}$ 7.4, for $10 \mathrm{~min}$.

For subsequent antibody staining, cells were washed with PBS and incubated in blocking solution ( $4 \%$ normal goat serum $/ 0.04 \%$ Triton $\mathrm{X}-100$ in PBS) for $15 \mathrm{~min}$, followed by vesicular glutamate transporter vGluT-1 primary antibody (Millipore Corporation) in blocking solution (1:2000 dilution for $3 \mathrm{~h}$ ). Cells were washed with PBS and then incubated with Alexa 647-conjugated anti-guinea pig antibody (1:500 in blocking solution; Millipore Corporation) for $30 \mathrm{~min}$. Coverslips were then washed with PBS and mounted with Fluoromount-G (Southern Biotechnology Associates).

For vGluT-1/Munc13-1 costaining, cells were fixed in cold $100 \%$ methanol for $10 \mathrm{~min}$. Munc13-1 primary antibody (Synaptic Systems) was used at 1:1000. Secondary antibodies were Alexa 488conjugated anti-guinea pig and Alexa 633-conjugated anti-rabbit (both at 1:500; Invitrogen). For vGluT-1/Rim 1 costaining, cells were fixed in $4 \%$ paraformaldehyde in PBS. Rim 1 primary antibody (BD Biosciences) was used at 1:500. Secondary antibodies were Alexa 488conjugated anti-guinea pig and Alexa 647-conjugated anti-mouse (both at 1:500; Invitrogen). Bassoon antibody (Synaptic Systems) was used at 1:500 with cells fixed in 4\% paraformaldehyde in PBS. Rab3 antibody (Synaptic Systems) was used at 1:500 with cells fixed in 4\% paraformaldehyde in PBS. Syntaxin 1A (Synaptic Systems) was used at 1:2000 with cells fixed in 4\% paraformaldehyde in PBS. VAMP2 (Synaptic Systems) was used at 1:1000 with cells fixed in 4\% paraformaldehyde $/ 0.2 \%$ glutaraldehyde in PBS.

For experiments in which Munc13-1 and vGluT-1 immunocytochemistry was performed in conjunction with FM1-43 uptake, FM1-43FX labeling was performed identically to other experiments, but cells were fixed in $4 \%$ paraformaldehyde $/ 0.025 \%$ glutaraldehyde. vGluT- 1 antibody was used at 1:2000 and Munc13-1 antibody was used at 1:500. Secondary antibodies were Alexa 555-conjugated anti-rabbit and Alexa 633-conjugated anti-guinea pig (both at 1:500; Invitrogen). For experiments in which Rim1 and vGluT-1 immunocytochemistry was performed in conjunction with FM1-43 uptake, FM1-43FX labeling was performed identically to other experiments, but cells were fixed in $4 \%$ paraformaldehyde $/ 0.03 \%$ glutaraldehyde. Secondary antibodies were cyanine 3 (Cy3)-conjugated anti-mouse and Alexa 647-conjugated antiguinea pig (both at 1:500; Invitrogen).

For transfection experiments in which Munc13-1 and vGluT-1 immunocytochemistry was performed in neurons expressing synaptophysinYFP, cells were fixed in $4 \%$ paraformaldehyde in PBS and permeabilized in $0.1 \%$ Triton X-100. vGluT-1 was used at 1:2000, and Munc13-1 was used at 1:500. Secondary antibodies were Cy3-conjugated anti-guinea pig and Alexa 647-conjugated anti-rabbit.

All stains were examined by confocal microscopy performed using a $60 \times$ objective (1.4 numerical aperture), a C1 scanning confocal laser attached to an inverted Eclipse TE2000 microscope (Nikon), and Z-1 software (Nikon). An observer naive to experimental conditions acquired images of representative fields in $z$-stack using alternating excitation by the 488,543 , and/or 633 laser lines as appropriate. Gain settings, dwell time, field of view size, and $z$-stack parameters were kept constant for all images within an experiment. Monochrome images were converted into projected images and analyzed using MetaMorph software (Universal Imaging). Ten puncta per field and five fields per condition were analyzed for each experiment. Staining was 
thresholded separately for images from each laser line. vGluT-1positive puncta were always defined first, without reference to images from other laser lines. Regions identified in the vGluT-1 image were then transferred to other images. Regions with FM1-43FX staining exceeding a criterion of $>10$ pixels were considered active presynaptic terminals (Moulder et al., 2006, 2008). For experiments in which Rim1 or Munc13-1 immunoreactivity was examined in nonsynaptic locations, intensity was measured in a $5 \times 5$ pixel square placed immediately adjacent to the region of a defined synaptic punctum but still within the clearly visible neurite.

Electrophysiology. Solitary microisland neurons were used for all electrophysiology experiments. Control and experimental conditions were always performed on sibling cultures from the same litter and plating and on the same day of recording.

Whole-cell recordings were performed using an Axopatch 1D amplifier (Molecular Devices) and a Digidata 1322 acquisition board (Molecular Devices). Electrodes had resistances of 3-5 $\mathrm{M} \Omega$, and access resistance was compensated $80-100 \%$. In all instances, cells were excluded from analysis if a leak current $>300 \mathrm{pA}$ was observed. For recording, the culture medium was exchanged for recording solution containing the following (in $\mathrm{mM}$ ): $138 \mathrm{NaCl}, 4 \mathrm{KCl}, 2 \mathrm{CaCl}_{2}, 1 \mathrm{MgCl}_{2}, 10$ glucose, 10 HEPES, and $0.025 \mathrm{D}-\mathrm{APV}, \mathrm{pH}$ 7.25. The whole-cell pipette solution contained the following (in $\mathrm{mM}$ ): $140 \mathrm{~K}$-gluconate, $0.5 \mathrm{CaCl}_{2}, 5 \mathrm{EGTA}$, and $10 \mathrm{HEPES}$, $\mathrm{pH}$ 7.25. For synaptic recordings, cells were stimulated with $1.5 \mathrm{~ms}$ pulses to $0 \mathrm{mV}$ from $-70 \mathrm{mV}$ to evoke transmitter release (Mennerick et al., 1995). For hypertonic solution ( $0.5 \mathrm{~m}$ sucrose), application time was $3 \mathrm{~s}$. Sucrose responses were integrated to include responses beneath the transient peak of the response to $10 \%$ of the steady-state response.

Immunoblotting. For cultured neurons, treated cells were washed twice in PBS and then lysed in $1 \times$ reducing Laemmli's sample buffer plus protease inhibitors $(10 \mu \mathrm{g} / \mathrm{ml}$ leupeptin and $20 \mu \mathrm{g} / \mathrm{ml}$ aprotinin $)$. One 35 $\mathrm{mm}$ dish was lysed per condition; four lanes of each condition (lysed separately) were loaded per experiment to account for dish-to-dish variability in cell number. For hippocampal slices, tissue was sonicated in radioimmunoprecipitation assay buffer $(150 \mathrm{~mm} \mathrm{NaCl}, 50 \mathrm{~mm}$ Tris, $0.5 \%$ deoxycholic acid, $0.1 \%$ SDS, $1 \%$ Triton X-100, and 2.5 mм EDTA, pH 8.0) plus protease inhibitors. Three to four slices per condition were loaded per experiment. Slices in each condition were matched for their anteroposterior position within the hippocampus.

Individual samples were separated under reducing conditions using $4-12 \%$ Bis-Tris or $3-8 \%$ Tris-acetate NuPAGE gels (Invitrogen) and transferred to nitrocellulose. Blots were incubated in $3 \%$ nonfat dried milk (NFDM) dissolved in TTBS buffer (20 mм Tris, $0.137 \mathrm{M} \mathrm{NaCl}$, and $0.1 \%$ Tween $20, \mathrm{pH}$ 7.6). Primary and HRP-conjugated secondary antibodies were diluted in 1\% NFDM in TTBS. Bands were detected with Lumigen-TMA6 (GE Healthcare) or SuperSignal West Pico Chemiluminescent Substrate (Pierce) and captured digitally using the Kodak ImageStation $440 \mathrm{CF}$. Densitometry was performed using the Kodak 1D Image Analysis software.

Primary antibody concentrations were as follows: Munc13-1 (1:1000), Rim1 (1:1000), Bassoon (1:500), Rab 3 (1:2000), Rabphilin (1:500; Abcam), Munc18 (1:10,000; BD Bioscience), $\alpha$ SNAP (1:500; Santa Cruz Biotechnology), SNAP-25 (1:2000; Millipore Corporation), Syntaxin1 (1:1000; Synaptic Systems), VAMP2 (1:100,000), and vGluT-1 (1:500). Blots were stripped with Restore Western Blot Stripping Buffer (Pierce) and reprobed with tubulin antibody (1:4000, Sigma) as a total protein control or SV2 antibody (1:1000; Developmental Studies Hybridoma Bank, University of Iowa) as a presynaptic protein control.

Proteasome enzymatic assay. Proteasome enzymatic activity was measured using a microtiter plate assay as described previously (Qiu et al., 2000; Snider et al., 2002; Lee et al., 2004). Cells were lysed in $10 \mathrm{~mm}$ Tris, $1 \mathrm{~mm}$ EDTA, 2 mм ATP, 20\% glycerol, and 4 mм DTT before sonication. Protein concentrations were measured using a Coomassie assay. Protein $(2.5 \mu \mathrm{g})$ was assayed for the LLVY (Leu-Leu-Val-Tyr) proteasome activity in a $50 \mu \mathrm{l}$ reaction containing the following: $0.5 \mathrm{~mm}$ EDTA, $40 \mu \mathrm{M}$ LLVY-7-amino-4-methylcoumarin (AMC) (Sigma), and $50 \mathrm{~mm}$ Tris$\mathrm{HCl}, \mathrm{pH}$ 8.0. After $1 \mathrm{~h}$ at $37^{\circ} \mathrm{C}$, the reaction was quenched with ice-cold water, and fluorescence was measured on a CytoFluor II plate reader (Perseptive Systems) with an excitation/emission of 360/440 nm. Back- ground fluorescence was determined by omitting extract. A standard curve was constructed using AMC (Sigma). Samples were assayed in quadruplicate.

Toxicity assays. Toxicity of proteasome inhibitors was assessed after treatment with two independent assays. First, neurons were counted under phase-contrast optics using an inverted Nikon TE300 microscope. Cells were counted as live if soma retained a smooth phase-bright appearance with visible, intact neuritic processes. Second, propidium iodide (PI) was added to a final concentration of $0.5 \mu \mathrm{g} / \mathrm{ml}$, and cultures were returned to a $37^{\circ} \mathrm{C}$ incubator for $1 \mathrm{~h}$. Fluorescent nuclei were then counted on an inverted Nikon TE200S microscope. In all instances, the rater was naive to the experimental conditions.

Reagents. All reagents were obtained from Sigma unless otherwise indicated. MG-132 (carbobenzoxy-L-leucyl-L-leucyl-L-leucinal) and epoxomycin were obtained from Biomol. MDL 28170 (carbobenzoxyvalinyl-phenylalaninal) was obtained from EMD Biosciences.

Data acquisition and statistics. pClamp software, version 9 (Molecular Devices), was used for electrophysiology data acquisition and analysis for all experiments. Data plots were created with SigmaPlot software (SPSS). Data are presented in the figures and text as mean \pm SEM. Paired and unpaired $t$ tests were used to evaluate statistical significance between experimental conditions.

\section{Results}

Proteasome inhibition interferes with induction of persistent presynaptic silencing

The UPS is a regulator of postsynaptic function at both glutamate and GABA synapses (Burbea et al., 2002; Colledge et al., 2003; Ehlers, 2003; Pak and Sheng, 2003; Patrick et al., 2003; Bingol and Schuman, 2006; Saliba et al., 2007). Recently, increasing evidence suggests an additional role for the UPS in modulating neurotransmitter release at mammalian synapses. The UPS directly regulates levels of the synaptic vesicle priming protein Rim $1 \alpha$ (Yao et al., 2007), and work in hippocampal neurons confirms that the proteasome can modulate the recycling pool of synaptic vesicles (Willeumier et al., 2006). We therefore tested whether the UPS plays a role in the induction of persistent presynaptic silencing, which we have shown previously is likely attributable to a defect in synaptic vesicle priming (Moulder et al., 2006). Presynaptic silencing can be induced with different degrees of depolarizing challenge; we focused here on brief depolarization to avoid confounding effects of intervention on development and survival (see Materials and Methods).

We depolarized hippocampal neurons in the presence or absence of $3 \mu \mathrm{M}$ MG-132, a reversible proteasome inhibitor. We first assessed presynaptic function using FM1-43 uptake; silent terminals are identified as glutamate synapses that immunolabel with an antibody against vGluT-1 but do not label with FM dyes. Similar to our previous studies, we found that depolarization produced strong presynaptic silencing (Fig. $1 A, D$ ). However, addition of the proteasome inhibitor simultaneous with the depolarizing stimulus prevented the induction of presynaptic silencing (Fig. 1A,D). MG-132 addition alone had no significant effect on the percentage of silent synapses (Fig. $1 D$ ), but we did observe that proteasome inhibition increased the average integrated intensity of individual FM1-43 puncta by $29.1 \%$ $\left[1.32 \pm 0.12 \times 10^{6}\right.$ arbitrary units (AU) for control baseline; $1.87 \pm 0.23 \times 10^{6} \mathrm{AU}$ for control plus MG-132; $\left.p<0.05\right]$. Because FM1-43 integrated intensity reflects the size of the recycling pool of synaptic vesicles at individual terminals, this is consistent with published evidence that proteasome inhibition increases the size of the recycling vesicle pool (Willeumier et al., 2006). Although our measured increase of $29.1 \%$ is smaller than the effect of proteasome inhibition reported by Willeumier and colleagues, our experiments were performed at 11-14 DIV. A 

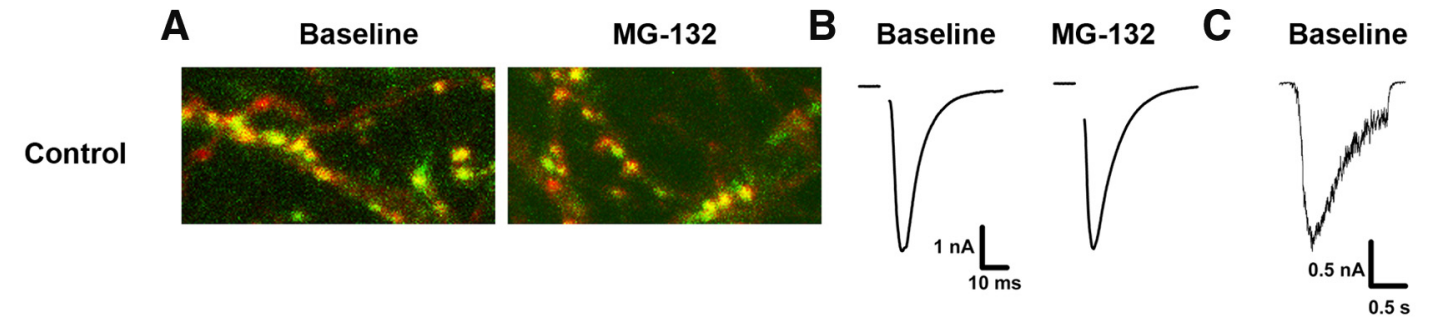

MG-132
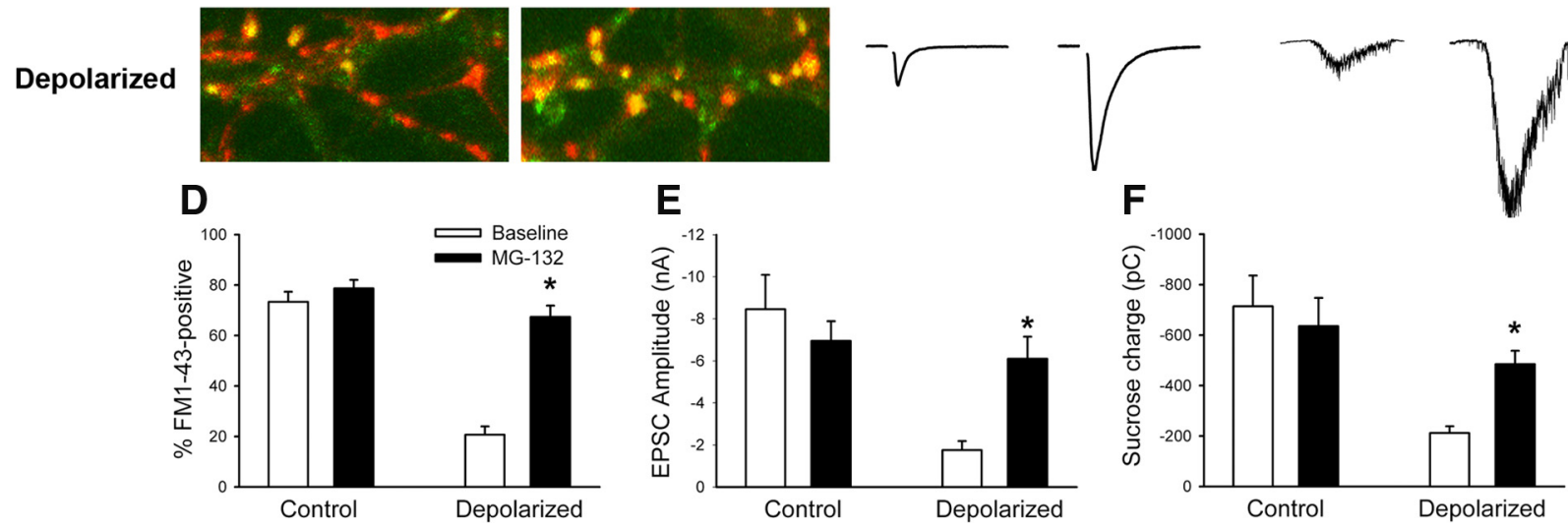

Figure 1. Proteasome inhibition prevents induction of persistent presynaptic silencing. $A$, Merged images of FM1-43FX stain of active synapses (green) and vGluT-1 immunoreactivity (red) to reveal all glutamatergic terminals. Images are from control (untreated) hippocampal neurons, after a $4 \mathrm{~h}$ exposure to $3 \mu \mathrm{M} M G-132$, or after depolarization in the presence or absence of MG-132. $\boldsymbol{B}, \boldsymbol{C}$, Representative traces of autaptic action potential-evoked $(\boldsymbol{B})$ and sucrose-evoked $(\boldsymbol{C})$ EPSCs recorded under the same conditions as in $\boldsymbol{A}$. $\boldsymbol{D}-\boldsymbol{F}$, Summary of quantitative results from the FM1-43/vGluT-1 correspondence assay $(\boldsymbol{D})$, from action potential-evoked EPSCS $(\boldsymbol{E})$, and responses to hypertonic sucrose application $(\boldsymbol{F}) . n=15$ each; ${ }^{*} p<0.001$ compared with the depolarized baseline condition.

larger effect on recycling pool size might have been detectable in older neurons (Willeumier et al., 2006). Average FM1-43 integrated intensity of active synapses was unchanged in depolarized neurons (with or without MG-132) compared with control.

Because the FM1-43/vGluT-1 assay measures all releasecompetent vesicles at individual synapses, we also wanted to test whether proteasome inhibition prevented effects of depolarization on glutamate release triggered by single action potentials. For these studies, we used autaptic hippocampal cultures. MG132 at $3 \mu \mathrm{M}$ prevented the decrease in EPSC amplitude induced by depolarization when administered simultaneously with the challenge (Fig. $1 B, E$ ). We also used brief hypertonic sucrose application to measure the size of the readily releasable pool (RRP) of vesicles (Rosenmund and Stevens, 1996; Moulder and Mennerick, 2005) in the same neurons in which we recorded EPSCs. As with EPSC amplitude, proteasome inhibition prevented the decrease in sucrose response charge induced by depolarization (Fig. 1C,F). We did not, however, detect significantly larger EPSCs or sucrose responses during proteasome inhibition in control cultures (Fig. $1 B, C, E, F$ ), despite the FM1-43-defined increase in the size of the recycling vesicle pool. This apparent discrepancy could be attributable to the fact that EPSC and sucrose measurements rely on the combined outputs of thousands of synapses, and the synapse number variability among neurons obscures small differences at individual synapses. Alternatively, because the RRP is only a subset of the recycling pool of vesicles (Pyle et al., 2000), our result could also suggest that proteasome inhibition increases the size of the recycling pool not by modulating RRP size but by mobilizing the reserve vesicle pool.

\section{Effects of proteasome inhibition on persistent presynaptic} silencing are specific and unrelated to neurotoxicity Proteasome inhibition in intact cells, particularly neurons, can be complicated by both toxicity and a lack of specificity of the inhib- itors. To ensure that our observed effects on glutamate release were attributable to a specific blockade of proteasome enzymatic activity, we performed a series of controls. Three protease enzymatic activities are associated with the core domain: a chymotrypsinlike activity, a trypsin-like activity, and a peptidylglutamyl peptidase activity (for review, see Smalle and Vierstra, 2004). The chymotrypsin-like activity (cleaving at LLVY) is considered to be the main, or most active, activity of the proteasome (Orlowski and Wilk, 2000). We therefore measured the chymotrypsin-like activity of the proteasome in hippocampal neurons exposed to 0.3 or $3 \mu \mathrm{M}$ MG-132 for $4 \mathrm{~h}$ (Fig. $2 A$ ). We found that $0.3 \mu \mathrm{M}$ MG-132 inhibited $50.9 \pm 4.4 \%$ and $3 \mu \mathrm{M} \mathrm{MG}-132$ inhibited $83.2 \pm 0.4 \%$ of control levels of chymotrypsin-like activity. Acute addition of $1 \mu \mathrm{M}$ MG-132 to control lysate inhibited $93.3 \pm 1.0 \%$ of control levels of chymotrypsin-like activity. These results indicate that $4 \mathrm{~h}$ treatment with $3 \mu \mathrm{M} \mathrm{MG}$-132 inhibited a significant amount of proteasome enzymatic activity in hippocampal neurons. To test whether this treatment was neurotoxic, neuronal cell counts were performed on sibling cultures after $4 \mathrm{~h}$ exposure to MG-132. Neither 0.3 nor $3 \mu \mathrm{M} \mathrm{MG}-132$ had a significant effect on neuronal cell number (Fig. $2 B$ ). In parallel experiments, we also assessed PI exclusion in neurons after $4 \mathrm{~h}$ exposure to MG132 to assay dying neurons. The number of neurons labeled with PI was unchanged after MG-132 treatment (Fig. 2C). These results are consistent with our previous work in cortical and striatal neurons, which indicated that $\geq 16 \mathrm{~h}$ of exposure to proteasome inhibitors is required to induce neurotoxicity (Snider et al., 2002).

MG-132 has also been reported to inhibit calpain activity (Meng et al., 1999). To test whether calpains could mediate persistent presynaptic silencing, we depolarized neurons in the presence or absence of $20 \mu \mathrm{M}$ MDL 28170, also known as calpain inhibitor III (Pottorf et al., 2006). MDL 28170 did not prevent induction of presynaptic silencing, as assessed by FM1-43 uptake 
(Fig. $2 D$ ), whereas $3 \mu \mathrm{M}$ MG-132 did prevent silencing in sibling cultures. In addition, we also reproduced the antisilencing effects of MG-132 with a more specific and irreversible proteasome inhibitor, epoxomycin (Meng et al., 1999), at $30 \mathrm{~nm}$ (Fig. 2 E). Because $4 \mathrm{~h}$ epoxomycin treatment also resulted in a significant loss of neurons $(38.0 \pm 16.2 \%$ decrease; $p<0.01 ; n=3)$, we performed all subsequent experiments with MG-132. These results confirm that the synaptic effects of MG-132 are attributable to proteasome blockade and not calpain inhibition, a particularly important point because calpains could be activated by calcium influx caused by depolarization.

\section{Depolarization, but not cAMP signaling, modulates proteasome enzymatic activity in hippocampal neurons}

Because MG-132 prevented induction of persistent presynaptic silencing (Fig. 1), we next asked whether depolarization alters proteasome enzymatic activity. We depolarized hippocampal neurons in the presence or absence of MG-132 and then measured the chymotrypsin-like activity of the proteasome. Four hours of strong depolarization significantly increased proteasome enzymatic activity, which was inhibited by inclusion of MG-132 (Fig. 3A). Our previous work showed that potentiation of CAMP signaling also prevents induction of persistent presynaptic silencing (Moulder et al., 2008), although the mechanism underlying this protective effect is unclear. For this reason, we also asked whether $50 \mu \mathrm{M}$ forskolin (FSK), a potent adenylyl cyclase activator, altered proteasome enzymatic activity. As seen in Figure $3 B$, FSK treatment had no effect on proteasome activity, either under control conditions or after depolarization. This suggests that cAMP signaling modulates presynaptic function either downstream of proteasome activity or through a parallel pathway.

\section{Munc13-1 and Rim1 protein levels are reduced during induction of persistent presynaptic silencing}

If UPS-mediated protein degradation is an integral part of the mechanisms underlying persistent presynaptic silencing, then one or more protein targets of this pathway must be essential for maintaining presynaptic function. Our previous work has shown that synaptic vesicle number does not change at individual terminals after induction of presynaptic silencing (Moulder et al., 2006) and that levels of synaptic vesicle proteins such as SV2 and vGluT-1 are also unchanged (Moulder et al., 2004, 2006, 2008). Furthermore, given that synaptic vesicle priming is likely compromised in silenced presynaptic terminals (Moulder et al., 2006), we hypothesized that molecules implicated in priming are the critical targets of the UPS. Munc13-1 stood out as an attractive candidate target for two reasons: first, the similarity of the presynaptic silencing phenotype (as demonstrated in Fig. 1) and that of Munc13-1 $1^{-1-}$ neurons; second, the selective dependence of glutamatergic, but not GABAergic, neurons on Munc13-1 for neurotransmitter release (Augustin et al., 1999; Varoqueaux et al., 2002), which could potentially explain the lack of an effect of strong depolarization on the RRP of GABAergic neurons (Moulder et al., 2004). Although expression of a Munc13-1-YFP fusion
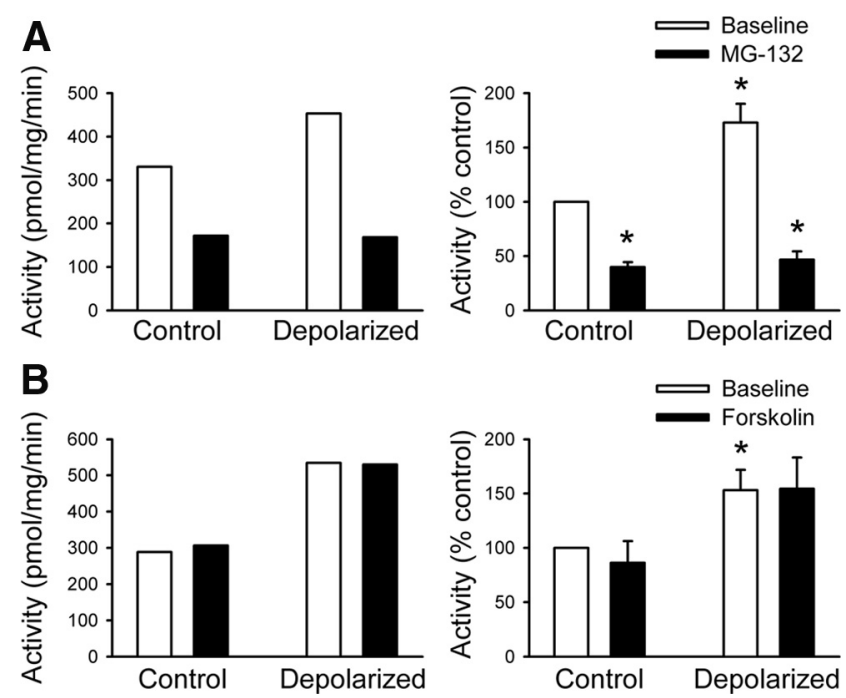

Figure 3. Strong depolarization increases proteasome enzymatic activity. $\boldsymbol{A}$, Representative example (left) and normalized summary (right) of the chymotrypsin-like (LLVY) activity of the proteasome measured in lysates from control neurons, after a $4 \mathrm{~h}$ exposure to $3 \mu \mathrm{M} \mathrm{MG}-132$, or after depolarization in the presence or absence of MG-132. $\boldsymbol{B}$, Representative example (left) and normalized summary (right) of proteasome activity in control neurons, after a 4 h exposure to 50 $\mu \mathrm{M}$ FSK, or after depolarization in the presence or absence of FSK. For summarized results, $n=4(\boldsymbol{A})$ or $3(\boldsymbol{B})$ experiments. ${ }^{*} p<0.05$ compared with the control baseline condition.

construct is not regulated by the proteasome (Kalla et al., 2006), substantial evidence has confirmed that Dunc13, the Drosophila ortholog of Munc13 isoforms, is degraded by the proteasome (Aravamudan and Broadie, 2003; Speese et al., 2003).

We therefore examined Munc13-1 levels at glutamate synapses (identified using vGluT-1 labeling) by immunofluorescence after depolarization. Munc13-1 levels were decreased at synaptic sites after a depolarizing challenge to produce silencing (Fig. 4A, $C, E$; average decrease of $41.2 \pm 4.8 \%$ in $C$ and $27.0 \pm$ $7.4 \%$ in $E$ ). Consistent with the idea that the protein was, in fact, degraded rather than redistributed, no accompanying increase in 

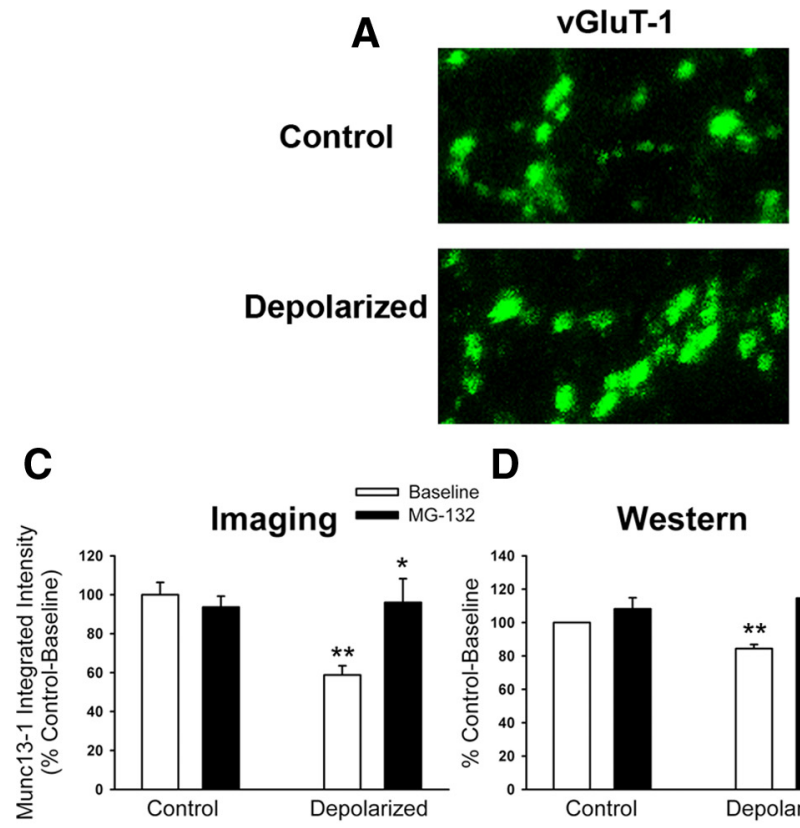

D

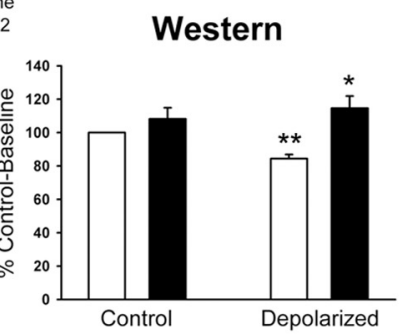

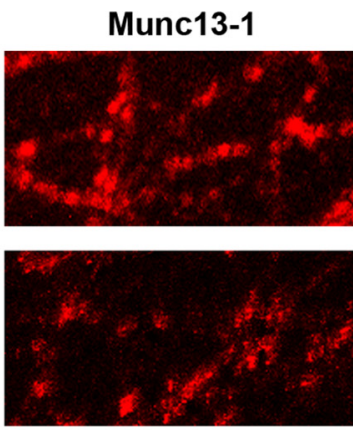

E
B

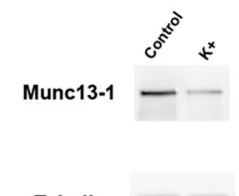

sv2

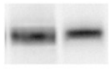

Figure 4. Strong depolarization decreases Munc13-1 levels, which are rescued by MG-132 or forskolin. $\boldsymbol{A}$, Representative images of vGluT-1 and Munc13-1 immunostaining in control neurons and after depolarization. $\boldsymbol{B}$, Representative Western blot image after depolarization, illustrating a decrease in Munc13-1 protein compared with a general protein marker, tubulin, or the synaptic protein SV2. $\boldsymbol{C}, \boldsymbol{E}$, Summary of the average integrated intensity of Munc13-1 immunostaining at glutamate synapses after depolarization in the presence or absence of $3 \mu \mathrm{m}$ MG-132 or $50 \mu \mathrm{m}$ FSK. $n=15$ each. For $\boldsymbol{C}^{* *} p<0.001$ compared with the control baseline condition and ${ }^{*} p<0.005$ compared with the depolarized baseline condition. For $\boldsymbol{E}$, $p<0.01$ compared with the control baseline condition, ${ }^{* *} p<0.03$ compared with the control baseline condition, and ${ }^{*} p<0.001$ compared with the depolarized baseline condition. $\boldsymbol{D}, \boldsymbol{F}$, Summary of normalized quantitative results from Western blot analyses in parallel experiments to $\boldsymbol{C}$ and $\boldsymbol{E}$. Munc13-1 protein was normalized to SV2 protein levels within sample. $n=3$ experiments each. For $\boldsymbol{D}$, ${ }^{* *} p<0.05$ compared with the control baseline condition and ${ }^{*} p<0.03$ compared with the depolarized baseline condition. For $\boldsymbol{F},{ }^{\#} p<0.01$ compared with the control baseline condition, ${ }^{* *} p<0.01$ compared with the control baseline condition, and ${ }^{*} p<0.03$ compared with the depolarized baseline condition.

Munc13-1 immunofluorescence was seen in neurite areas adjacent to synaptic sites (average fluorescence intensity, $8680.9 \pm$ 1610.6 AU for control and 6314.6 \pm 312.5 AU for depolarized neurons; $p>0.05)$. Western blot analysis confirmed that total cellular levels of Munc13-1 were also decreased by depolarization compared with either the general protein marker tubulin or the synaptic vesicle protein SV2 (Fig. $4 B, D, F$; average decrease of $15.6 \pm 2.5 \%$ in $D$ and $23.3 \pm 3.9 \%$ in $F$ ). We next assessed whether the decreases in Munc13-1 protein expression were blocked by agents that prevent induction of persistent presynaptic silencing. Addition of either $3 \mu \mathrm{M} \mathrm{MG}-132$ or $50 \mu \mathrm{M}$ FSK maintained both synaptic (Fig. 4C,E) and cellular (Fig. 4D,F) levels of Munc13-1 in the face of depolarization. Surprisingly, FSK addition also increased synaptic and cellular levels of Munc13-1 from control levels in the absence of depolarization (Fig. $4 E, F)$.

Because it is unclear whether mammalian Munc13-1 is a direct target for degradation by the proteasome, we also examined the levels of the priming protein Rim 1 the $\alpha$ isoform of which is a target of proteasome degradation (Yao et al., 2007). We first examined Rim1 levels at glutamate synapses by immunofluorescence after depolarization, using an anti-Rim1 antibody that recognizes a central epitope within both $\operatorname{Rim} 1 \alpha$ and $\operatorname{Rim} 1 \beta$ isoforms (Kaeser et al., 2008b). Similar to Munc13-1, synaptic Rim1 protein levels decreased after depolarization (Fig. $5 A, C, E$; average decrease of $35.6 \pm 6.2 \%$ in $C$ and $37.4 \pm 9.8 \%$ in $E$ ). Also, adjacent neuritic levels of Rim 1 showed a similar decrease (average fluorescence intensity, 25,670.2 $\pm 3271.8 \mathrm{AU}$ for control and $7251.2 \pm 1830.4$ AU for depolarized neurons; $p>0.001)$. Western blot analysis confirmed that depolarization depressed cellular levels of Rim $1 \alpha$ by $25.7 \pm 6.2 \%$ when normalized to tubulin levels and by $21.8 \pm 4.4 \%$ when normalized to SV2 levels (Fig.
$5 B, D, F$; average decrease of $31.8 \pm 8.9 \%$ in $D$ and $14.3 \pm 1.7 \%$ in $F)$. Although expressed at a lower level than $\operatorname{Rim} 1 \alpha$, the newly identified, smaller Rim $1 \beta$ isoform (Kaeser et al., 2008b) was reduced as well $(15.9 \pm 7.7 \%$ [tubulin] or $18.2 \pm 3.8 \%$ [SV2]). Addition of either $3 \mu \mathrm{M}$ MG-132 or $50 \mu \mathrm{M}$ FSK maintained both synaptic (Fig. 5C,E) and cellular (Fig. 5D,F) levels of Rim $1 \alpha$ in the face of depolarization. Again, FSK addition also increased synaptic and cellular levels of Rim1 proteins from control levels in the absence of depolarization (Fig. $5 E, F$ ).

Although Munc13-1 and Rim1 protein expression levels mirrored alterations in glutamate presynaptic function, it was unclear whether these changes were essential for the induction of the persistent presynaptic silencing phenotypes. Therefore, we asked whether protein expression level correlated with presynaptic function at individual glutamate terminals. We depolarized hippocampal neurons and assessed presynaptic function using FM1-43 uptake, followed by immunostaining for vGluT-1 and Munc13-1 or vGluT-1 and Rim1. Average Munc13-1 and Rim1 levels were decreased at glutamate synapses after depolarization, consistent with Figures 4 and 5 (30.7 $\pm 7.5 \%$ decrease for Munc13-1 and $37.5 \pm 3.1 \%$ decrease for Rim 1$)$. However, if we separately analyzed the Munc13-1 and Rim1 levels at FM1-43positive ("active") versus FM1-43-negative ("inactive") synapses, we found that Munc13-1 and Rim1 levels were consistently higher in active synapses (Fig. 6). This was true both under basal conditions and after depolarization, which induced many more inactive synapses (Fig. 6B,D). Our own and others' previous results have demonstrated that a fraction of hippocampal presynaptic terminals are silent (inactive) even under basal conditions (Rosenmund et al., 2002; Altrock et al., 2003; Moulder et al., 2006; Ting et al., 2007). Furthermore, we could demonstrate a correlation between FM1-43 uptake at individual synapses and 

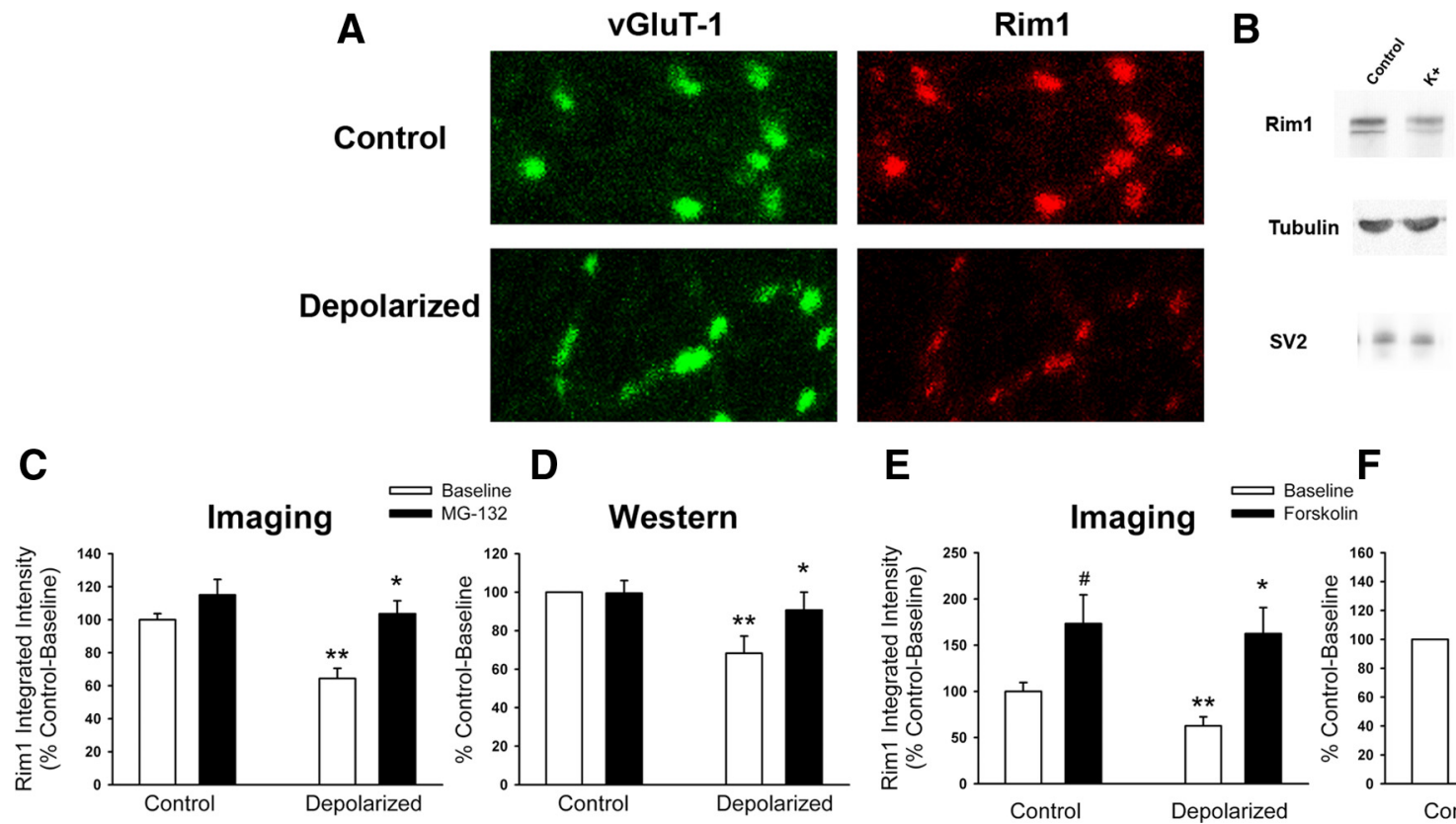

Western
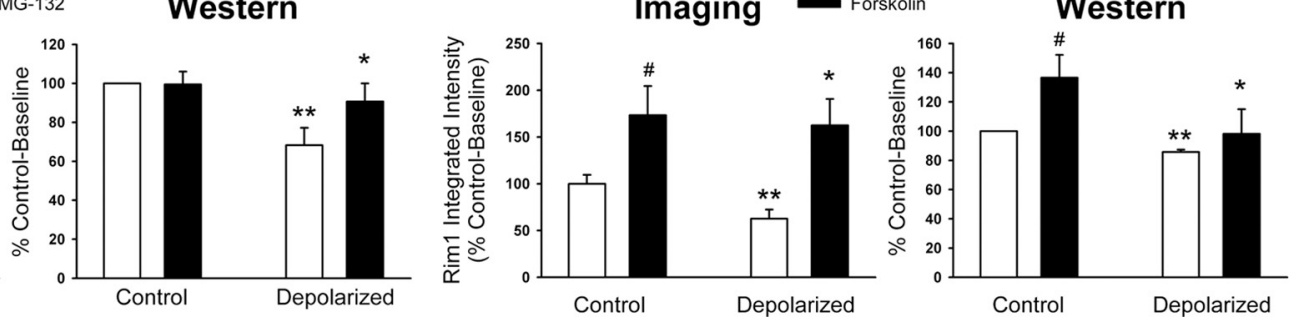

Figure 5. Depolarization decreases Rim 1 protein levels, which are rescued by MG-132 or forskolin. $\boldsymbol{A}$, Representative images of vGluT-1 and Rim $1 \alpha / \beta$ immunostaining in control neurons and after depolarization. $\boldsymbol{B}$, Representative Western blot image after depolarization, illustrating a decrease in Rim $1 \alpha$ protein compared with a general protein marker, tubulin, or the synaptic protein SV2. $\boldsymbol{C}, \boldsymbol{E}$, Summary of the average integrated intensity of Rim $1 \alpha / \beta$ immunostaining at glutamate synapses after depolarization in the presence or absence of $3 \mu \mathrm{m} M G-132$ or $50 \mu \mathrm{m}$ FSK. $n=$ $15-25$ each. For $C$, ${ }^{* *} p<0.001$ compared with the control baseline condition and ${ }^{*} p<0.01$ compared with the depolarized baseline condition. For $\boldsymbol{E}_{\text {, }}{ }^{\#} p<0.001$ compared with the control baseline condition, ${ }^{* *} p<0.005$ compared with the control baseline condition, and ${ }^{*} p<0.001$ compared with the depolarized baseline condition. $D, F$, Summary of normalized quantitative results from Western blot analyses in parallel experiments to $\boldsymbol{C}$ and $\boldsymbol{E}$. Rim $1 \alpha$ protein was normalized to SV2 protein levels within sample. $n=3$ experiments each. For $\boldsymbol{D}$, ${ }^{* *} p<0.03$ compared with the control baseline condition and ${ }^{*} p<0.05$ compared with the depolarized baseline condition. For $F,{ }^{\#} p<0.01$ compared with the control baseline condition, ${ }^{* *} p<0.02$ compared with the control baseline condition, and ${ }^{*} p<0.05$ compared with the depolarized baseline condition.

the Munc13-1 (Fig. 6E) or Rim1 (Fig. 6F) levels at those synapses. The present data therefore suggest that synaptic Munc13-1 and Rim 1 expression levels may partially dictate the ability of an individual terminal to undergo proper synaptic vesicle cycling.

Because the stability of the entire active zone is dependent on electrical activity under some conditions (Kalla et al., 2006), our results with Munc13-1 and Rim1 proteins caused us to question whether depolarization might trigger a turnover of the active zone. We therefore examined the cellular and/or synaptic levels of a number of other critical presynaptic proteins (Fig. 7). We generally focused our analysis on proteins implicated in the synaptic vesicle priming process, as well as known protein kinase A (PKA) substrates, given the ability of cAMP signaling to influence presynaptic silencing (Moulder et al., 2008). We did not observe a significant change in any presynaptic proteins other than Munc13-1 and $\operatorname{Rim} 1 \alpha / \beta$ after depolarization. Therefore, although we have not exhausted all possibilities, our results suggest that the measured decreases in Munc13-1 and Rim1 proteins represent a relatively selective and targeted increase in protein degradation.

\section{$\operatorname{Rim} 1 \alpha$ overexpression prevents induction of presynaptic} silencing and associated decreases in Munc13-1

If $\operatorname{Rim} 1 \alpha$ loss is a direct or indirect cause of presynaptic silencing, overexpression of $\operatorname{Rim} 1 \alpha$ might overcome degradation and prevent silencing. Therefore, we asked whether induction of persistent presynaptic silencing could be prevented with overexpression of $\operatorname{Rim} 1 \alpha$. We selected $\operatorname{Rim} 1 \alpha$ for these experiments because Munc13-1 protein expression appears to depend on the continued presence of Rim1 proteins; total cellular levels of Munc13-1 are decreased in brains from $R i m 1 \alpha^{-/-}$animals (Schoch et al., 2002), whereas $\operatorname{Rim} 1 \alpha$ levels are not altered in
Munc13-1 $1^{-/-}$neurons (Augustin et al., 1999). Furthermore, a ubiquitin ligase termed Scrapper is responsible for the tagging of $\operatorname{Rim} 1 \alpha$ with ubiquitin and its subsequent degradation. In Scrapper ${ }^{-1-}$ neurons, both $\operatorname{Rim} 1 \alpha$ and Munc13-1 levels are increased, and in neurons from Scrapper transgenic (overexpressing) neurons, both Rim $1 \alpha$ and Munc13-1 levels are decreased (Yao et al., 2007). Therefore, we hypothesized that the observed changes in Munc13-1 levels during silencing may be linked secondarily to decreases in $\operatorname{Rim} 1 \alpha$ levels.

Hippocampal neurons in autaptic cultures were transfected with GFP with or without $\operatorname{Rim} 1 \alpha$ at 9-11 DIV, and neurons were depolarized 1 to $2 \mathrm{~d}$ later. Presynaptic function was assessed by measuring action potential-evoked EPSC amplitude and the charge of the sucrose-defined RRP (Fig. 8). We found that Rim $1 \alpha$ overexpression slightly increased EPSC amplitude and the size of the RRP under control conditions, although this effect was not statistically significant (Fig. $8 C, D)(p>0.05)$. When neurons were depolarized, however, $\operatorname{Rim} 1 \alpha$ overexpression prevented the induction of persistent presynaptic silencing. Both action potential-evoked EPSCs and sucrose responses were maintained at control levels. These results indicate that presynaptic function is preserved in the face of depolarization if Rim 1 protein levels are sufficiently high.

We also asked whether Rim $1 \alpha$ overexpression prevented the decrease in synaptic Munc13-1 levels induced by depolarization. For these experiments, we used a synaptophysin-YFP fusion construct to mark the presynaptic terminals of transfected neurons. Neurons were transfected with synaptophysin-YFP with or without $\operatorname{Rim} 1 \alpha$ at 9-14 DIV, and neurons were depolarized $1 \mathrm{~d}$ later, followed by immunocytochemistry for Munc13-1 and vGluT-1. A representative example of Munc13-1 and vGluT-1 immunostaining of synaptophysin-YFP-positive synapses is 

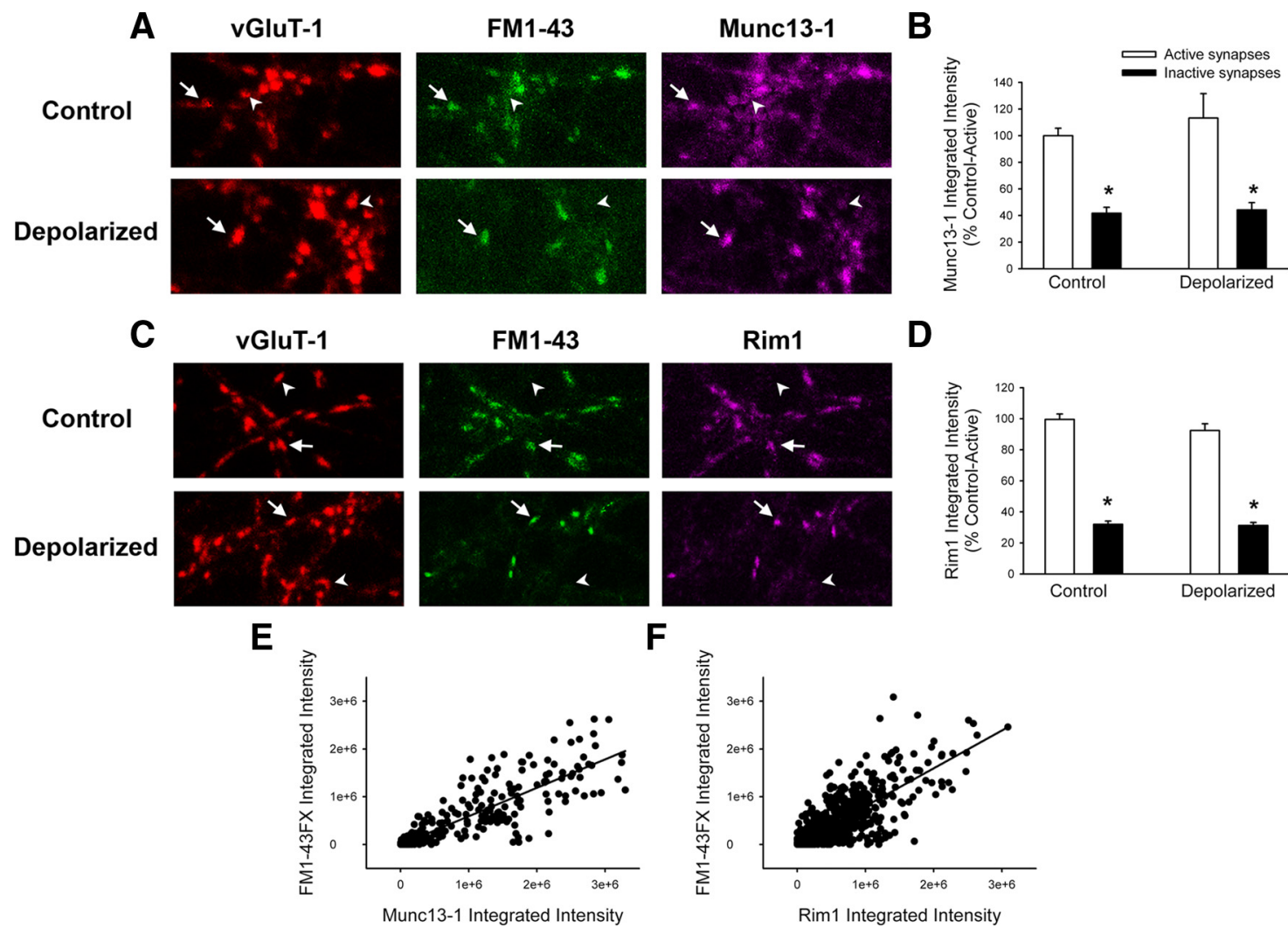

$\mathbf{D}$
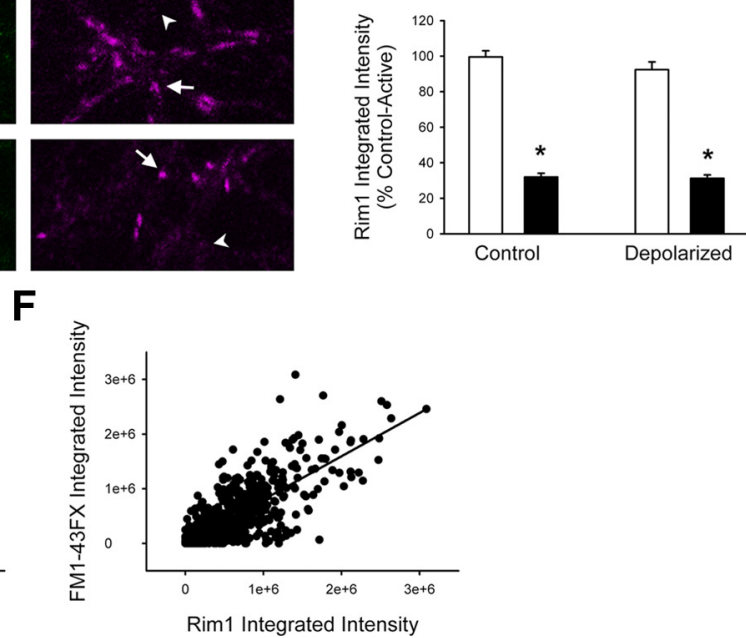

Figure 6. Synaptic Munc13-1 and Rim1 levels correlate with presynaptic function. $\boldsymbol{A}$, Representative images of FM1-43FX uptake and Munc13-1 immunostaining at glutamate synapses under control conditions and after depolarization. Note that Munc13-1 levels are lower at inactive synapses (FM1-43 ${ }^{-} / \mathrm{vGluT}^{-} 1^{+}$; arrowheads) than at active synapses (FM1-43 ${ }^{+} / \mathrm{vGluT}-1^{+}$; arrows) in both conditions, although the percentage of inactive synapses in control cultures is much lower overall (see Fig. 1D). $\boldsymbol{B}$, Summary of average integrated intensity of Munc13-1 immunostaining at active (FM1-43 ${ }^{+}$) and inactive (FM1-43 ${ }^{-}$) glutamate synapses. $n=220$ (active) or 80 (inactive) for control and 72 (active) or 228 (inactive) for the depolarized condition. ${ }^{*} p 0.001$ compared with the active synapses in that condition. C, Representative images of FM1-43FX uptake and Rim1 immunostaining at glutamate synapses under control conditions and after depolarization. Rim 1 levels are also lower at inactive synapses (arrowheads) than at active synapses (arrows). Note that synaptic puncta size is slightly smaller in $\boldsymbol{C}$ than in $\boldsymbol{A}$ attributable to differences in cell fixation. $\boldsymbol{D}$, Summary of average integrated intensity of Rim 1 immunostaining at active and inactive glutamate synapses. $n=228$ (active) or 122 (inactive) for control and 93 (active) or 257 (inactive) for the depolarized condition. ${ }^{*} p<0.01$ compared with the active synapses in that condition. $\boldsymbol{E}, \boldsymbol{F}$, Measures of FM1-43FX integrated intensity values at individual synapses plotted as a function of the Munc13-1 $(\boldsymbol{E})$ or the $\operatorname{Rim} 1(\boldsymbol{F})$ integrated intensity values. Data are from the same glutamate synapses as in $\boldsymbol{B}$ and $\boldsymbol{D}$. For $\boldsymbol{E}, r^{2}=0.785 ; p<0.001$. For $\boldsymbol{F}, r^{2}=0.599 ; p<0.001$.

shown in supplemental Figure 1 (available at www.jneurosci. org as supplemental material). Consistent with our electrophysiology results, we found that $\operatorname{Rim} 1 \alpha$ overexpression maintained synaptic Munc13-1 levels at glutamate synapses after depolarization (Fig. $8 \mathrm{E}$ ). These data are also consistent with the idea that Munc13-1 protein stability is linked with Rim 1 protein expression. Therefore, degradation of Rim 1 proteins likely plays a causative role in the induction of persistent presynaptic silencing.

\section{Discussion}

Over the past decade, increasing attention has revealed the impact of the UPS on neuronal function. Potential defects in proteasomal degradation have been linked to many neurodegenerative diseases, such as Alzheimer's disease and Huntington's disease (for review, see Hegde and Upadhya, 2007). Even under physiological conditions, the UPS helps to regulate synaptogenesis and synaptic plasticity. Our results show a critical role for the UPS in the modulation of glutamate release from the presynaptic terminal. Furthermore, the observation that targeted degradation of the synaptic vesicle priming proteins Rim1 and Munc13-1 compromises glutamatergic signaling supports a prominent role for these proteins in the maintenance of presynaptic function. Our experiments suggest that neuronal activity exploits this pathway to elicit homeostatic downregulation of glutamate release after a period of increased activity.

Munc13-1 and Rim1 are selectively targeted during induction of presynaptic silencing

We observed a decrease in both the synaptic and cellular levels of Munc13-1 and Rim1 proteins after depolarization (Figs. 4, 5). These decreases were not attributable to a general turnover of the presynaptic active zone because several other proteins maintained their expression levels in the face of tonic depolarization (Fig. 7). Furthermore, overexpression of Rim $1 \alpha$ prevented the induction of persistent presynaptic silencing (Fig. 8). These data are consistent with the idea that Munc13-1 and Rim1 proteins play critical roles in synaptic vesicle release and suggest that Munc13-1 and Rim1 proteins are selectively targeted by electrical activity in the regulation of this process. We were surprised that $\operatorname{Rim} 1 \alpha$ overexpression did not significantly increase EPSC amplitude or RRP size under control conditions (Fig. 8) given that inhibition of Rim $1 \alpha$ degradation increases quantal glutamate release (Yao et al., 2007). This is likely attributable to cell-to-cell variability in synapse number in autaptic cultures, resulting in overlapping postsynaptic response sizes between the two treatment groups. 
Munc13-1 versus Rim1 proteins as direct targets of the UPS

Our immunoblot analyses revealed that cellular levels of both $\operatorname{Rim} 1 \alpha$ and the newly identified Rim $1 \beta$ isoform (Kaeser et al., 2008b) were decreased by depolarization. This suggests, but does not prove, that $\operatorname{Rim} 1 \beta$ is a direct target of the proteasome, as has been shown for $\operatorname{Rim} 1 \alpha$ (Yao et al., 2007). Related to this question is whether Munc13-1 is degraded by the proteasome or whether its stability relies instead on the presence or absence of Rim1 proteins. Substantial work has shown that Dunc13, the Drosophila ortholog of Munc13 isoforms, is degraded by the proteasome (Aravamudan and Broadie, 2003; Speese et al., 2003). However, one report suggests that a Munc13$1-$ YFP construct is not regulated by the proteasome (Kalla et al., 2006). In this instance, it is possible that the YFP moiety enhances Munc13-1 stability. The idea that Munc13-1 decreases are secondary to Rim 1 protein degradation stems from the observation that total cellular levels of Munc13-1, but not Munc13-2, are decreased in Rim $1 \alpha^{-1-}$ animals (Schoch et al., 2002). Conversely, $\operatorname{Rim} 1 \alpha$ levels are not altered in Munc13-1 $1^{-1-}$ neurons (Augustin et al., 1999). Our observation that $\operatorname{Rim} 1 \alpha$ overexpression can both prevent induction of persistent presynaptic silencing and maintain synaptic levels of Munc13-1 is consistent with the latter scenario. However, it would still be informative to determine whether Munc13-1 can be targeted directly for UPS-mediated degradation.

It is important to note that persistent presynaptic silencing is a plastic response to electrical activity or depolarization and that presynaptically silenced synapses regain function within hours (Moulder et al., 2004, 2008). In the context of the present results, it will be interesting to probe recovery mechanisms in more detail. Specifically, the question arises as to how synaptic vesicle cycling is restored after degradation of synaptic Munc13-1 and Rim1 proteins.

Munc13-1 and Rim1 levels correlate with presynaptic function

We also observed that presynaptic function is correlated with levels of Munc13-1 and Rim1 in glutamatergic neurons (Fig. 6). Notably, this was true even under basal levels of activity. Therefore, neurons likely use the mechanisms underlying persistent presynaptic silencing to maintain a fraction of inactive synapses even with physiological activity, as we have suggested previously (Moulder et al., 2006). The premise for examining Munc13-1 and Rim1 during and after a prolonged change in activity is that syn-

C

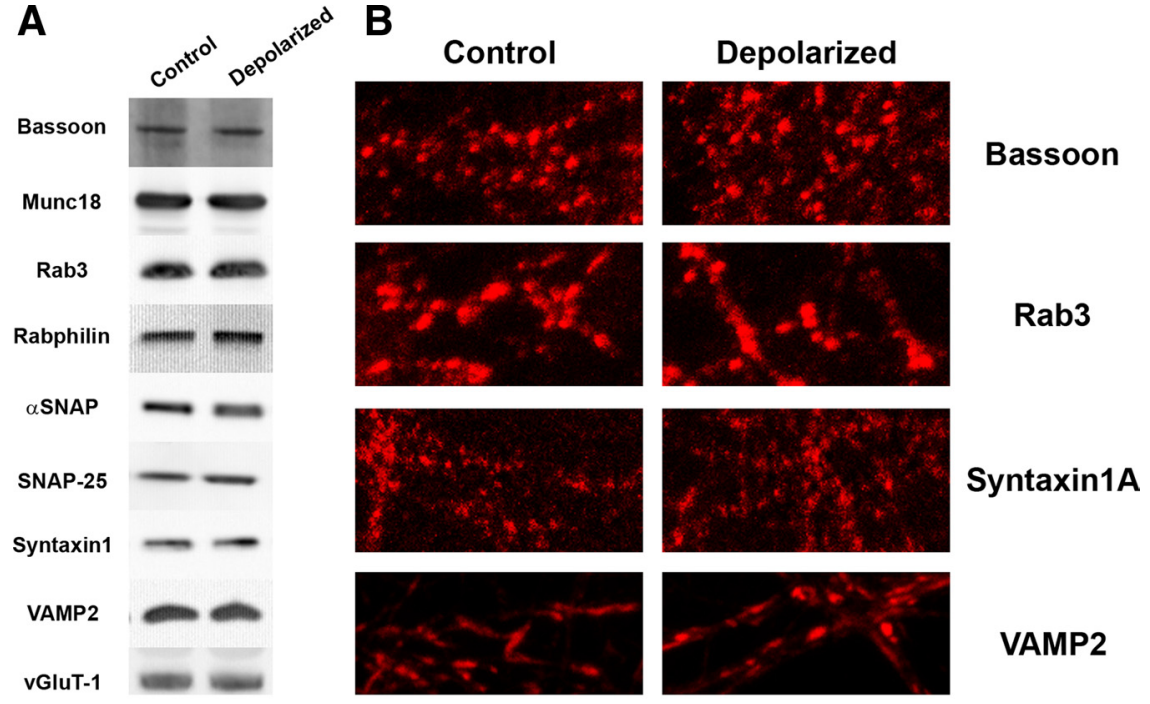

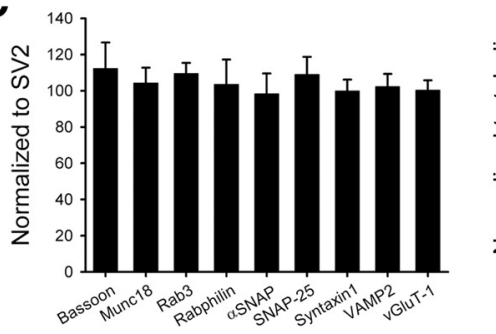
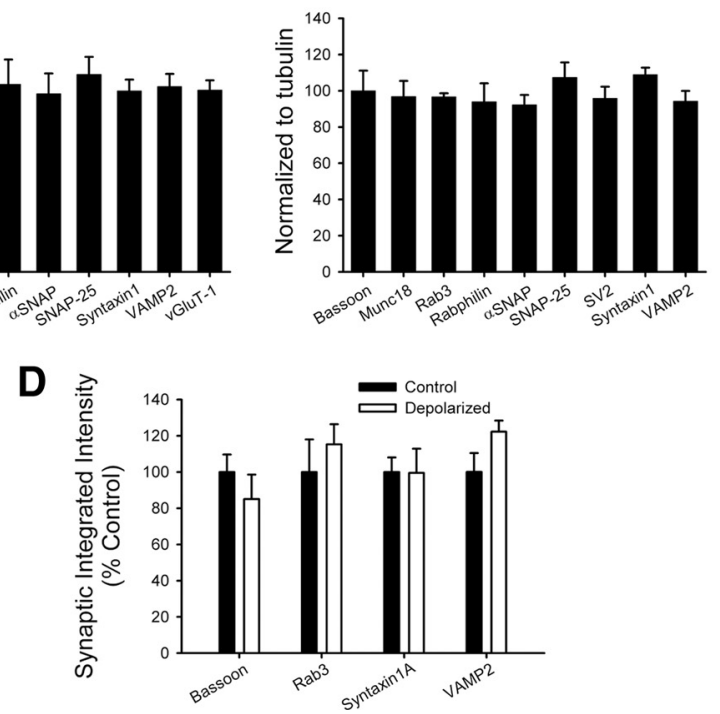

Figure 7. Several presynaptic proteins are unaffected by depolarization. $\boldsymbol{A}$, Representative Western blot images from control neurons and after depolarization. As noted in Materials and Methods, some Western blots were performed using tissue from acute hippocampal slices to increase the amount of total protein available for Western blot analysis. We have confirmed previously that persistent presynaptic silencing can be induced in acute hippocampal slices (Moulder et al., 2004). $\boldsymbol{B}$, Representative images of immunostaining in control neurons and after depolarization. Note that synaptic puncta size can vary attributable to differences in cell fixation and permeabilization. $\boldsymbol{C}$, Summary of normalized quantitative results from Western blot analyses. The candidate proteins were normalized to SV2 (left) or tubulin (right) protein levels within sample. $n=3$ experiments each. Values shown are the percentage of control measured in the depolarized condition. No statistically significant differences were observed after depolarization. vGluT-1 was normalized to SV2 only because of the similarity in size with tubulin. Examples of SV2 Western blot images can be seen in Figures 4 and 5 . $D$, Summary of the average integrated intensity of candidate protein immunostaining at glutamate synapses after depolarization. Analysis was restricted to glutamate synapses through colocalization with vGluT-1 immunostaining. $n=$ 10 -15 each. No statistically significant differences were observed after depolarization. A lack of difference in synaptic SV2 and vGluT-1 immunostaining after depolarization has been reported previously (Moulder et al., 2004, 2006).

aptic levels of these proteins may determine whether or not a given synapse has functional synaptic vesicle cycling. We appreciate, however, that, although we have examined several presynaptic proteins, including many implicated in synaptic vesicle priming (Fig. 7), we have not eliminated the possibility that other proteins may also contribute to presynaptic silencing mechanisms. Given that the roles of many presynaptic proteins are still ill defined, this possibility would be virtually impossible to test fully. Regardless of which proteins are involved, overexpression of a single candidate protein, $\operatorname{Rim} 1 \alpha$, rescued presynaptic func- 


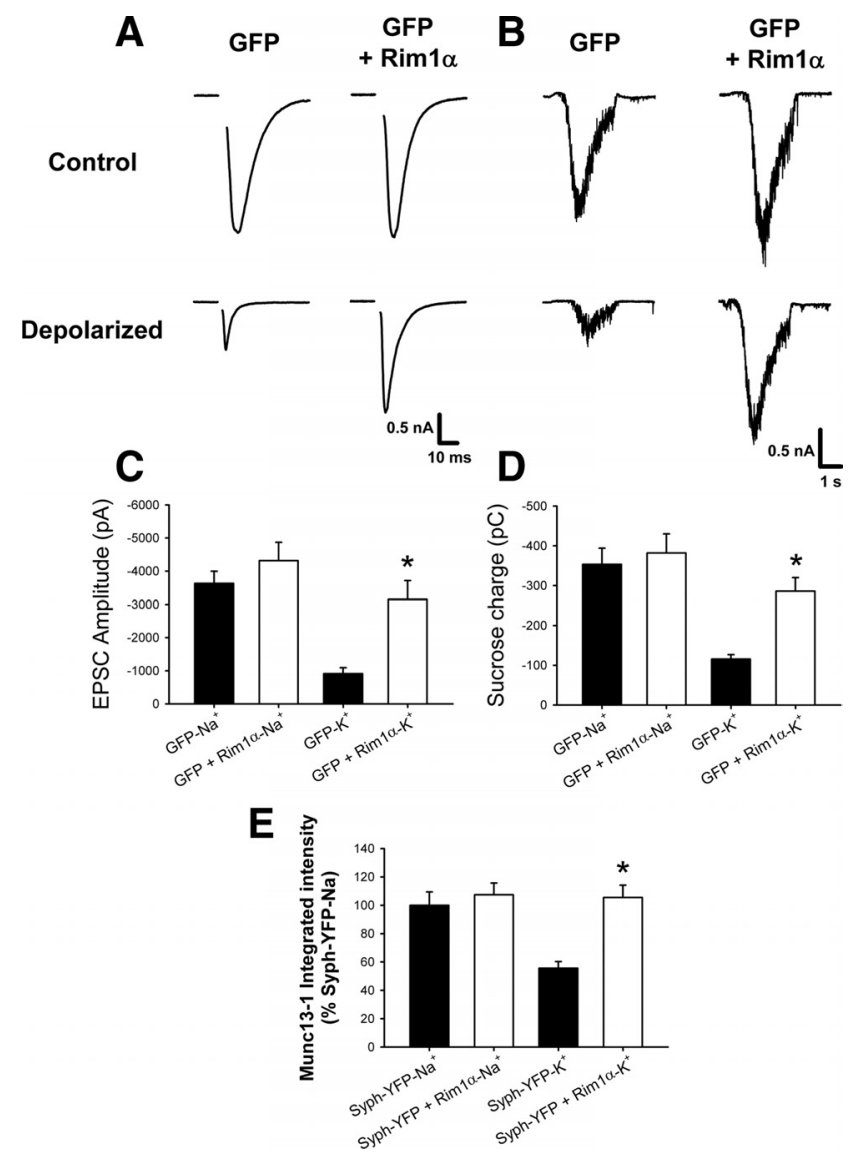

Figure 8. Rim $1 \alpha$ overexpression prevents induction of persistent presynaptic silencing. $\boldsymbol{A}, \boldsymbol{B}$, Representative traces of autaptic action potential-evoked $(\boldsymbol{A})$ and sucrose-evoked $(\boldsymbol{B})$ EPSCS recorded under control conditions and after depolarization in neurons transfected with GFP alone or GFP plus $\operatorname{Rim} 1 \alpha$. C, $\boldsymbol{D}$, Summary of quantitative results from action potentialevoked EPSCS $(\boldsymbol{C})$ and responses to hypertonic sucrose application $(\boldsymbol{D})$ in transfected neurons. $n=13$ each; ${ }^{*} p<0.001$ compared with the depolarized condition transfected with GFP alone. $\boldsymbol{E}$, Summary of Munc13-1 integrated intensity at glutamatergic terminals of transfected neurons. $n=214-453$ synapses per condition; ${ }^{*} p<0.001$ compared with the depolarized condition transfected with synaptophysin-YFP (Syph-YFP) alone.

tion (Fig. 8). The most parsimonious explanation is that $\operatorname{Rim} 1 \alpha$ loss is directly important for synaptic silencing, and overcoming this loss prevents silencing.

\section{Strong depolarization modulates proteasome enzymatic activity}

Depolarization likely resulted in decreased levels of Munc13-1 and Rim1 proteins because depolarization increased proteasome enzymatic activity (Fig. 3). These data are consistent with previously published work in which depolarization increased degradation of a GFP-based proteasomal activity reporter (Bingol and Schuman, 2006). Potassium depolarization has also been shown to decrease total levels of protein ubiquitination (Chen et al., 2003), which may occur through a separate mechanism but could in fact be attributable to enhanced degradation of ubiquitinated proteins.

The mechanism by which tonic depolarization or increased electrical activity may modulate proteasome enzymatic activity is unclear. Surprisingly, although the UPS has been extensively investigated, the factors that upregulate or downregulate proteasome function are just beginning to be revealed (Zhang et al., 2007b). Proteasome enzymatic activity can be altered through changes in the subunit composition of the $20 \mathrm{~S}$ proteasome core or through differences in associating proteins, including components of the 19 S proteasome cap (Young et al., 2008). Core subunits and associating proteins can also be modified posttranslationally (Zhang et al., 2003), including via phosphorylation (Zhang et al., 2007b), with mixed effects on function.

\section{Potential interactions between cAMP signaling and the UPS} Phosphorylation of proteasome subunits via PKA has been reported to increase proteasome enzymatic activity (Upadhya et al., 2006; Zhang et al., 2007a). In our experiments, we found that $4 \mathrm{~h}$ treatment with FSK had no effect on proteasome enzymatic activity, either under control conditions or coincident with depolarization (Fig. 3). FSK should increase cAMP levels, which in turn should activate PKA. Differences in the length of PKA activation (Zhang et al., 2007a) or in the preparation used during PKA activation (intact neurons vs cell extracts) (Upadhya et al., 2006) likely explain why we did not detect an effect of FSK on proteasome activity in our system.

Our results also leave open the question of how cAMP signaling pathways and the UPS-mediated degradation interact in terms of modulating presynaptic function. Both FSK and MG132 prevent induction of presynaptic silencing (Fig. 1) (Moulder et al., 2008), and both block depolarization-induced decreases in Munc13-1 and Rim 1 proteins (Figs. 4, 5). Rim $1 \alpha$ has two consensus sites for PKA phosphorylation (Lonart et al., 2003) and is a direct target of the UPS (Yao et al., 2007), thereby making it an attractive candidate for the intersection of these two pathways. However, the importance of the serine 413 PKA phosphorylation site in several models of synaptic plasticity has been questioned recently (Kaeser et al., 2008a), suggesting that the mechanism might be considerably more complicated. The significance of serine 413 phosphorylation is not known, but it does not appear to affect Rim1 protein trafficking (for review, see Kaeser and Südhof, 2005). It is possible that Rim1 phosphorylation affects its stability or, more specifically, its targeting to and degradation by the proteasome. Such protection by PKA phosphorylation has been described for other proteins (Gastel et al., 1998; Schomerus et al., 2000; Hino et al., 2005). Last, because forskolin, but not MG-132, treatment increased Munc13-1 and Rim1 levels even under control conditions (Figs. 4, 5), it is possible that cAMP signaling modulates new transcription and translation of these proteins, as opposed to their degradation.

\section{Modulation of proteasome activity: special concerns in neurons}

Proteasome activity is higher at synapses than in the nucleus and is regulated differentially (Upadhya et al., 2006). However, the specificity of depolarization-induced increases in proteasome activity, in terms of both spatial restrictions and target selectivity, must be delineated. The ability of electrical activity to interact with the proteasome to regulate synaptic vesicle pools (Willeumier et al., 2006) is likely to fall under similar governance. Proteasome inhibition increases the frequency of miniature EPSC events, which is likely attributable in part to decreased Rim $1 \alpha$ degradation (Yao et al., 2007), but the full complement of presynaptic UPS effects is far from clear. Our results suggest that the UPS is recruited by neurons to help maintain target firing rates by depressing glutamate release in the face of increased electrical activity. It will be of great interest to determine the precise triggers for this mechanism as well as the means by which signaling pathways can alter its outcome. 


\section{References}

Altrock WD, tom Dieck S, Sokolov M, Meyer AC, Sigler A, Brakebusch C, Fässler R, Richter K, Boeckers TM, Potschka H, Brandt C, Löscher W, Grimberg D, Dresbach T, Hempelmann A, Hassan H, Balschun D, Frey JU, Brandstätter JH, Garner CC, Rosenmund C, Gundelfinger ED (2003) Functional inactivation of a fraction of excitatory synapses in mice deficient for the active zone protein bassoon. Neuron 37:787-800.

Aravamudan B, Broadie K (2003) Synaptic Drosophila UNC-13 is regulated by antagonistic G-protein pathways via a proteasome-dependent degradation mechanism. J Neurobiol 54:417-438.

Augustin I, Rosenmund C, Südhof TC, Brose N (1999) Munc13-1 is essential for fusion competence of glutamatergic synaptic vesicles. Nature 400:457-461.

Bingol B, Schuman EM (2006) Activity-dependent dynamics and sequestration of proteasomes in dendritic spines. Nature 441:1144-1148.

Burbea M, Dreier L, Dittman JS, Grunwald ME, Kaplan JM (2002) Ubiquitin and AP180 regulate the abundance of GLR-1 glutamate receptors at postsynaptic elements in C. elegans. Neuron 35:107-120.

Chen H, Polo S, Di Fiore PP, De Camilli PV (2003) Rapid Ca ${ }^{2+}$-dependent decrease of protein ubiquitination at synapses. Proc Natl Acad Sci U S A 100:14908-14913.

Colledge M, Snyder EM, Crozier RA, Soderling JA, Jin Y, Langeberg LK, Lu H, Bear MF, Scott JD (2003) Ubiquitination regulates PSD-95 degradation and AMPA receptor surface expression. Neuron 40:595-607.

Ding M, Chao D, Wang G, Shen K (2007) Spatial regulation of an E3 ubiquitin ligase directs selective synapse elimination. Science 317:947-951.

Ding Q, Keller JN (2001) Proteasome inhibition in oxidative stress neurotoxicity: implications for heat shock proteins. J Neurochem 77:1010-1017.

Ehlers MD (2003) Activity level controls postsynaptic composition and signaling via the ubiquitin-proteasome system. Nat Neurosci 6:231-242.

Fioravante D, Liu RY, Byrne JH (2008) The ubiquitin-proteasome system is necessary for long-term synaptic depression in Aplysia. J Neurosci 28:10245-10256.

Gastel JA, Roseboom PH, Rinaldi PA, Weller JL, Klein DC (1998) Melatonin production: proteasomal proteolysis in serotonin $\mathrm{N}$-acetyltransferase regulation. Science 279:1358-1360.

Haas KF, Broadie K (2008) Roles of ubiquitination at the synapse. Biochim Biophys Acta 1779:495-506.

Hegde AN, Upadhya SC (2007) The ubiquitin-proteasome pathway in health and disease of the nervous system. Trends Neurosci 30:587-595.

Hino S, Tanji C, Nakayama KI, Kikuchi A (2005) Phosphorylation of betacatenin by cyclic AMP-dependent protein kinase stabilizes beta-catenin through inhibition of its ubiquitination. Mol Cell Biol 25:9063-9072.

Kaeser PS, Südhof TC (2005) Rim function in short- and long-term plasticity. Biochem Soc Trans 33:1345-1349.

Kaeser PS, Kwon HB, Blundell J, Chevaleyre V, Morishita W, Malenka RC, Powell CM, Castillo PE, Südhof TC (2008a) RIMlalpha phosphorylation at serine- 413 by protein kinase $\mathrm{A}$ is not required for presynaptic long-term plasticity or learning. Proc Natl Acad Sci USA 105:14680-14685.

Kaeser PS, Kwon HB, Chiu CQ, Deng L, Castillo PE, Südhof TC (2008b) RIM $1 \alpha$ and RIM $1 \beta$ are synthesized from distinct promoters of the RIM1 gene to mediate differential but overlapping synaptic functions. J Neurosci 28:13435-13447.

Kalla S, Stern M, Basu J, Varoqueaux F, Reim K, Rosenmund C, Ziv NE, Brose N (2006) Molecular dynamics of a presynaptic active zone protein studied in Munc13-1-enhanced yellow fluorescent protein knock-in mutant mice. J Neurosci 26:13054-13066.

Kay AR, Alfonso A, Alford S, Cline HT, Holgado AM, Sakmann B, Snitsarev VA, Stricker TP, Takahashi M, Wu LG (1999) Imaging synaptic activity in intact brain and slices with FM1-43 in C. elegans, lamprey, and rat. Neuron 24:809-817.

Lee CS, Tee LY, Warmke T, Vinjamoori A, Cai A, Fagan AM, Snider BJ (2004) A proteasomal stress response: pre-treatment with proteasome inhibitors increases proteasome activity and reduces neuronal vulnerability to oxidative injury. J Neurochem 91:996-1006.

Lonart G, Schoch S, Kaeser PS, Larkin CJ, Südhof TC, Linden DJ (2003) Phosphorylation of RIMlalpha by PKA triggers presynaptic long-term potentiation at cerebellar parallel fiber synapses. Cell 115:49-60.

Meeks JP, Mennerick S (2004) Selective effects of potassium elevations on glutamate signaling and action potential conduction in hippocampus. J Neurosci 24:197-206.

Meng L, Mohan R, Kwok BH, Elofsson M, Sin N, Crews CM (1999) Epoxomicin, a potent and selective proteasome inhibitor, exhibits in vivo antiinflammatory activity. Proc Natl Acad Sci U S A 96:10403-10408.

Mennerick S, Que J, Benz A, Zorumski CF (1995) Passive and synaptic properties of hippocampal neurons grown in microcultures and in mass cultures. J Neurophysiol 73:320-332.

Moulder KL, Mennerick S (2005) Reluctant vesicles contribute to the total readily releasable pool in glutamatergic hippocampal neurons. J Neurosci 25:3842-3850.

Moulder KL, Meeks JP, Shute AA, Hamilton CK, de Erausquin G, Mennerick S (2004) Plastic elimination of functional glutamate release sites by depolarization. Neuron 42:423-435.

Moulder KL, Jiang X, Taylor AA, Olney JW, Mennerick S (2006) Physiological activity depresses synaptic function through an effect on vesicle priming. J Neurosci 26:6618-6626.

Moulder KL, Jiang X, Taylor AA, Shin W, Gillis KD, Mennerick S (2007) Vesicle pool heterogeneity at hippocampal glutamate and GABA synapses. J Neurosci 27:9846-9854.

Moulder KL, Jiang X, Chang C, Taylor AA, Benz AM, Conti AC, Muglia LJ, Mennerick S (2008) A specific role for $\mathrm{Ca}^{2+}$-dependent adenylyl cyclases in recovery from adaptive presynaptic silencing. J Neurosci 28:5159-5168.

Orlowski M, Wilk S (2000) Catalytic activities of the $20 \mathrm{~S}$ proteasome, a multicatalytic proteinase complex. Arch Biochem Biophys 383:1-16.

Pak DT, Sheng M (2003) Targeted protein degradation and synapse remodeling by an inducible protein kinase. Science 302:1368-1373.

Patrick GN, Bingol B, Weld HA, Schuman EM (2003) Ubiquitin-mediated proteasome activity is required for agonist-induced endocytosis of GluRs. Curr Biol 13:2073-2081.

Pottorf WJ 2nd, Johanns TM, Derrington SM, Strehler EE, Enyedi A, Thayer SA (2006) Glutamate-induced protease-mediated loss of plasma membrane $\mathrm{Ca}^{2+}$ pump activity in rat hippocampal neurons. J Neurochem 98:1646-1656.

Pyle JL, Kavalali ET, Piedras-Rentería ES, Tsien RW (2000) Rapid reuse of readily releasable pool vesicles at hippocampal synapses. Neuron 28:221-231.

Qiu JH, Asai A, Chi S, Saito N, Hamada H, Kirino T (2000) Proteasome inhibitors induce cytochrome c-caspase-3-like protease-mediated apoptosis in cultured cortical neurons. J Neurosci 20:259-265.

Reaney SH, Johnston LC, Langston WJ, Di Monte DA (2006) Comparison of the neurotoxic effects of proteasomal inhibitors in primary mesencephalic cultures. Exp Neurol 202:434-440.

Rose K, Goldberg MP, Choi DW (1992) Cytotoxicity in murine cortical cell culture. In: In vitro biological systems: methods in toxicology (Tyson CA, Frazier JM, eds), pp 46-60. San Diego: Academic.

Rosenmund C, Stevens CF (1996) Definition of the readily releasable pool of vesicles at hippocampal synapses. Neuron 16:1197-1207.

Rosenmund C, Sigler A, Augustin I, Reim K, Brose N, Rhee JS (2002) Differential control of vesicle priming and short-term plasticity by Munc13 isoforms. Neuron 33:411-424.

Saliba RS, Michels G, Jacob TC, Pangalos MN, Moss SJ (2007) Activitydependent ubiquitination of $\mathrm{GABA}_{\mathrm{A}}$ receptors regulates their accumulation at synaptic sites. J Neurosci 27:13341-13351.

Schoch S, Castillo PE, Jo T, Mukherjee K, Geppert M, Wang Y, Schmitz F, Malenka RC, Südhof TC (2002) RIMlalpha forms a protein scaffold for regulating neurotransmitter release at the active zone. Nature 415:321-326.

Schomerus C, Korf HW, Laedtke E, Weller JL, Klein DC (2000) Selective adrenergic/cyclic AMP-dependent switch-off of proteasomal proteolysis alone switches on neural signal transduction: an example from the pineal gland. J Neurochem 75:2123-2132.

Smalle J, Vierstra RD (2004) The ubiquitin 26 S proteasome proteolytic pathway. Annu Rev Plant Biol 55:555-590.

Snider BJ, Tee LY, Canzoniero LM, Babcock DJ, Choi DW (2002) NMDA antagonists exacerbate neuronal death caused by proteasome inhibition in cultured cortical and striatal neurons. Eur J Neurosci 15:419-428.

Speese SD, Trotta N, Rodesch CK, Aravamudan B, Broadie K (2003) The ubiquitin proteasome system acutely regulates presynaptic protein turnover and synaptic efficacy. Curr Biol 13:899-910.

Ting JT, Kelley BG, Lambert TJ, Cook DG, Sullivan JM (2007) Amyloid 
precursor protein overexpression depresses excitatory transmission through both presynaptic and postsynaptic mechanisms. Proc Natl Acad Sci U S A 104:353-358.

Turrigiano GG, Nelson SB (2004) Homeostatic plasticity in the developing nervous system. Nat Rev Neurosci 5:97-107.

Upadhya SC, Ding L, Smith TK, Hegde AN (2006) Differential regulation of proteasome activity in the nucleus and the synaptic terminals. Neurochem Int 48:296-305.

Varoqueaux F, Sigler A, Rhee JS, Brose N, Enk C, Reim K, Rosenmund C (2002) Total arrest of spontaneous and evoked synaptic transmission but normal synaptogenesis in the absence of Munc13-mediated vesicle priming. Proc Natl Acad Sci U S A 99:9037-9042.

Willeumier K, Pulst SM, Schweizer FE (2006) Proteasome inhibition triggers activity-dependent increase in the size of the recycling vesicle pool in cultured hippocampal neurons. J Neurosci 26:11333-11341.

Yao I, Takagi H, Ageta H, Kahyo T, Sato S, Hatanaka K, Fukuda Y, Chiba T, Morone N, Yuasa S, Inokuchi K, Ohtsuka T, Macgregor GR, Tanaka K,
Setou M (2007) SCRAPPER-dependent ubiquitination of active zone protein RIM1 regulates synaptic vesicle release. Cell 130:943-957.

Young GW, Wang Y, Ping P (2008) Understanding proteasome assembly and regulation: importance to cardiovascular medicine. Trends Cardiovasc Med 18:93-98.

Zhang F, Su K, Yang X, Bowe DB, Paterson AJ, Kudlow JE (2003) O-GlcNAc modification is an endogenous inhibitor of the proteasome. Cell 115:715-725.

Zhang F, Hu Y, Huang P, Toleman CA, Paterson AJ, Kudlow JE (2007a) Proteasome function is regulated by cyclic AMP-dependent protein kinase through phosphorylation of Rpt6. J Biol Chem 282:2246022471.

Zhang F, Paterson AJ, Huang P, Wang K, Kudlow JE (2007b) Metabolic control of proteasome function. Physiology 22:373-379.

Zhao Y, Hegde AN, Martin KC (2003) The ubiquitin proteasome system functions as an inhibitory constraint on synaptic strengthening. Curr Biol 13:887-898. 